\title{
Mismatch Responses to Pitch Changes in Early Infancy
}

\author{
Chao He, Lisa Hotson, and Laurel J. Trainor
}

\begin{abstract}
We investigated the emergence of discriminative responses to pitch by recording 2-, 3-, and 4-month-old infants' electroencephalogram responses to infrequent pitch changes in piano tones. In all age groups, infants' responses to deviant tones were significantly different from responses to standard tones. However, two types of mismatch responses were observed simultaneously in the difference waves. An increase in the leftlateralized positive slow wave was prominent in 2-month-olds, present in 3-month-olds, but insignificant in 4-month-olds. A
\end{abstract}

\section{INTRODUCTION}

In recent years, event-related potentials (ERPs) have started to become an alternative method for studying auditory perception in infants because they do not depend on any overt responses, which are hard to obtain in infants. One ERP component, the mismatch negativity (MMN), has been extensively analyzed in studies of auditory discrimination in adults (for reviews, see Näätänen, Jacobsen, \& Winkler, 2005; Picton, Alain, Otten, Ritter, \& Achim, 2000; Schröger, 1998; Näätänen \& Alho, 1995, 1997). MMN is elicited by infrequent changes (deviant stimuli) in an ongoing stream of sound events (standard stimuli). MMN is most clearly seen in the difference wave obtained by subtracting the average response to standard stimuli from the average response to deviant stimuli. MMN appears as a negativity that peaks between 130 and 250 msec after stimulus onset depending on the difficulty of the discrimination and whether the deviants represent a change in pitch, duration, loudness, category, pattern, or other abstract sound feature. MMN manifests at the scalp as a bilateral frontal negativity concurrent with an inverted polarity at posterior and mastoid sites, consistent with primary generators in the two auditory cortices, and is thought to reflect the operation of updating sensory memory traces (Näätänen \& Alho, 1997). MMN is of particular interest in developmental studies because it does not require a behavioral response and, although affected by attention,

McMaster University, Canada faster adultlike mismatch negativity (MMN), lateralized to the right hemisphere, emerged at 2 months of age and became earlier and stronger as age increased. The coexistence and dissociation of two types of mismatch responses suggests different underlying neuromechanisms for the two responses. Furthermore, the earlier emergence of the MMN-like component to changes in pitch compared to other sound features implies that neural circuits involved in generating MMN-like responses have different maturational timetables for different sound features. attention is not required for its elicitation (e.g., Sussman, Ritter, \& Vaughan, 1998; Oades \& Dittmann-Balcar, 1995; Näätänen, Paavilainen, Tiitinen, Jiang, \& Alho, 1993). However, different studies reported different developmental trajectories for MMN in infants (e.g., Trainor et al., 2003; Trainor, Samuel, Desjardins, \& Sonnadara, 2001; Leppänen, Pihko, Eklund, \& Lyytinen, 1999; Leppänen, Eklund, \& Lyytinen, 1997; Cheour-Luhtanen, Alho, \& Sainio, 1996; Dehaene-Lambertz \& Dehaene, 1994; Alho, Sainio, Sajaniemi, Reinikainen, \& Näätänen, 1990). In the present study, we used high-resolution electroencephalogram (EEG) recordings to examine the development of mismatch responses to pitch changes in infants between 2 and 4 months of age.

Pitch perception is essential for both language and music acquisition in infancy. In speech, before infants understand the meanings of words, they are particularly attentive to the pitch contours (e.g., Fernald \& Mazzi, 1991; Werker \& McLeod, 1989; Fernald \& Kuhl, 1987), which convey emotional meaning. Pitch contours also provide cues that help infants to learn vowel categories (Trainor \& Desjardins, 2002) and delineate stress patterns that provide cues to lexical and grammatical boundaries (Jusczyk \& Derrah, 1987). In music, infants can remember the pitch patterns of melodies (Trehub, 2001) and recognize familiar melodies transposed in pitch (Plantinga \& Trainor, 2005) before they understand words or are sensitive to the particular scales used in their music system of exposure (Trainor \& Trehub, 1992). Behavioral studies have indicated that infants' frequency discrimination abilities improve rapidly over 
the first few months after birth (e.g., Olsho, Koch, Halpin, \& Carter, 1987; Sinnott \& Aslin, 1985; Maxon \& Hochberg, 1982; Olsho, Schoon, Sakai, Turpin, \& Sperduto, 1982; Kessen, Levine, \& Wendrich, 1979). For frequencies above $2 \mathrm{kHz}$ the thresholds of 6-month-olds approach those of adults for frequencies of $4 \mathrm{kHz}$. For frequencies below $2 \mathrm{kHz}$, infants can already detect changes of $3 \%$ at 3 months of age, although this is considerably above thresholds of adults (less than 1\%), and adult levels are not reached until well into childhood.

Since the first work by Alho et al. (1990), a number of studies have tried to elicit an MMN-like response in newborns and young infants by using pitch changes in pure or complex tones. Table 1 summarizes the methods and major findings of these studies. A negativity in the difference wave similar to the adult MMN has been reported in infants from preterm newborns to 1-yearolds (Hirasawa, Kurihara, \& Konishi, 2003; Čeponiené et al., 2000, 2002; Alho et al., 1990). However, a number of studies instead report a slow positive component in the difference wave ranging from 200 to $450 \mathrm{msec}$ (Leppänen, Guttorm, Pihko, Takkinen, \& Lyytinen, 2004; Morr, Shafer, Kreuzer, \& Kurtzberg, 2002; Cheour et al., 1999; Leppänen et al., 1997). A similar positive component has not been reported in the adult literature. Such conflicting results have also been reported in infant MMN studies using other sound features. For example, Cheour et al. (1998) and Cheour-Luhtanen et al. (1996) reported MMN-like negativity in newborns in response to vowel changes, whereas Friedrich, Weber, and Friederici (2004) and Friederici, Friedrich, and Weber (2002) reported a broad positivity using similar vowel sounds. Dehaene-Lambertz and Pena (2001), Dehaene-Lambertz (2000), and Dehaene-Lambertz and Dehaene (1994) found a positivity for syllable changes in newborns, 3-month-olds, and 4-month-olds. Trainor et al. (2001, 2003) reported a positive response in 2-month-old infants but a negative response in 6-monthold infants to fine temporal changes. However, for occasional changes in sound location, a negative response is not seen until 8 months of age (Sonnadara, Hotson, \& Trainor, 2005). To date, the question as to why two kinds of mismatch responses have been reported in infants is largely unresolved.

A number of hypotheses have been proposed for when positivities and when negativities will be seen. One possibility is that the state of the infant plays a role. For example, Friedrich et al. (2004) reported that negativities were more apparent in awake than in asleep infants. It has also been suggested that differences might reflect physiological characteristics of infants, but the findings are inconsistent across studies. Cheour et al. (1999) and Čeponiené et al. (2002) found a negativity in normal newborns but a positivity in cleft palate newborns. However, Pihko et al. (1999) reported a positivity in normal newborns and a negativity in newborns at risk for dyslexia. Leppänen et al. (2004) found a positivity for more mature newborns and a negativity for less mature newborns. It is possible that stimulus differences might be involved in these discrepancies, but this is unlikely because both Cheour et al. and Leppänen et al. used pure tones.

It is possible that methodological differences across studies may explain why some studies report negativities, whereas others report positivities (Leppänen et al., 2004). For example, placement of reference electrodes above versus below the sylvian fissure can cause the polarity of components generated in auditory cortex to invert when measured at the scalp. However, studies using the same reference channel have reported different polarities in infants (e.g., Čeponiené et al., 2002; Cheour et al., 1998; Leppänen et al., 1997, 1999), suggesting that reference differences are not responsible for the different mismatch polarities reported.

It is also possible that methodological differences across studies cause different neuromechanisms to be activated, leading to different observed responses. For example, interstimulus interval (ISI) can interact with the refractory periods of neural circuits. The negative response may reflect a nonrefractory memory-comparisonbased change detection process (Jacobsen \& Schröger, 2001), whereas the positivity may reflect a release from a refractory state because the stimulus change activates new neural circuits. Because refractory periods in early infancy would be expected to be longer due to immature myelination and synaptic functioning (Moore, 2002), optimal ISIs for MMN elicitation could be different in infants and in adults. However, studies using comparable ISIs have reported both the negative and the positive mismatch response in infants (e.g., Čeponiené et al., 2002; Leppänen et al., 1999). Thus, the effect of ISI alone cannot explain the positive versus negative mismatch responses.

An alternative possibility is that the negative and positive responses to change might reflect different neural processes, perhaps taking place in different cortical layers (Trainor et al., 2003). Morr et al. (2002) reported the presence of a negative response to pitch changes in infants under 12 months of age to large, but not to small, pitch changes, suggesting that different processes may be used for easy and hard discriminations. It is also possible that the negative response might reflect a true mismatch process, whereas the positive slow wave might represent an involuntary attention shift (Kushnerenko et al., 2002) or the automatic categorization of stimuli (Friedrich et al., 2004). Furthermore, if the two processes could occur at the same time, the positivity could potentially mask the negativity because of their overlapping latencies (Morr et al., 2002).

Because the positive mismatch response is reported as a broad slow wave, whereas the negative mismatch response is typically reported as an adultlike fast component, different filter settings may be able to distinguish these components. Most studies use a high-pass 
Table 1. Summary of Infant Mismatch Studies with Frequency Changes in Pure Tone or Complex Tones

\begin{tabular}{|c|c|c|c|c|c|}
\hline Study & Age and State & $\begin{array}{c}\text { fo of Standards }(S) \text { and } \\
\text { Deviants }(\mathrm{D})(\mathrm{Hz})\end{array}$ & Duration (d) and ISI (msec) & Filters $(\mathrm{Hz})$ & ERP Response \\
\hline Alho et al. (1990) & Newborns in quiet sleep & $\begin{array}{l}\text { Pure tone, } S=1000 \\
\quad D=1200\end{array}$ & $d=40$, ISI $=570$ & $0.5-30$ & $\begin{array}{l}\text { Negativity at } 296 \mathrm{msec}(\mathrm{Fz}) \text { and } \\
270 \mathrm{msec}(\mathrm{Cz})\end{array}$ \\
\hline Leppänen et al., 1997 & Newborns in quiet sleep & $\begin{array}{l}\text { Pure tone, } S=1000 \\
\quad D=1100,1300\end{array}$ & $d=74, \mathrm{ISI}=351$ & $<30$ & Positivity, $250-300 \mathrm{msec}$, both conditions \\
\hline Cheour et al., 1999 & $\begin{array}{l}\text { Newborns (healthy and } \\
\text { cleft palate groups) in } \\
\text { active sleep }\end{array}$ & $\begin{array}{l}\text { Pure tone, } S=1000 \\
\quad D=1100\end{array}$ & $d=100$, ISI $=700$ & $1-30$ & $\begin{array}{l}\text { Negativity, } 200-500 \mathrm{msec} \text { in healthy group } \\
\text { and three of nine in cleft palate group } \\
\text { Positivity in rest of cleft palate newborns }\end{array}$ \\
\hline Čeponiené et al., 2000 & $\begin{array}{l}\text { Newborns in active sleep } \\
\text { and 6-month-olds mostly } \\
\text { awake (healthy and cleft } \\
\text { palate group) }\end{array}$ & $\begin{array}{l}\text { Pure tone, } S=1000 \\
\quad D=1100\end{array}$ & $d=100$, ISI $=700$ & $1-30$ & $\begin{array}{l}\text { Negativity, } 80-300 \mathrm{msec} \text { in healthy } \\
\text { newborns and all 6-month-olds } \\
\text { No peak or smaller negativity } \\
(250-450 \mathrm{msec}) \text { in cleft palate } \\
\text { newborns }\end{array}$ \\
\hline Čeponiené et al., 2002 & Newborn in active sleep & $\begin{array}{l}\text { Harmonic tones with } \\
3 \text { partials, } S=500 \\
D=750\end{array}$ & $d=200$, ISI $=600$ & $1-15$ & Negativity, $80-300 \mathrm{msec}$ in $81 \%$ of subjects \\
\hline Kushnerenko et al., 2002 & $\begin{array}{l}\text { Infants recorded every } \\
3 \text { months from newborn } \\
\text { to } 12 \text { months old, kept } \\
\text { awake except newborns in } \\
\text { active sleep, others awake }\end{array}$ & $\begin{array}{l}\text { Harmonic tones with } \\
\text { three partials, } S=500 \\
D=750\end{array}$ & $d=100$, ISI $=700$ & $1-15$ & $\begin{array}{l}\text { Negativity, } 80-300 \mathrm{msec} \text { and positivity } \\
250-450 \mathrm{msec} \text { in } 75 \% \text { of infants at } \\
\text { each age, but MMN not consistent } \\
\text { within subjects across age }\end{array}$ \\
\hline Morr et al., 2002 & $\begin{array}{l}\text { Infants } 2-47 \text { months state } \\
\text { unknown }\end{array}$ & $\begin{array}{l}\text { Pure tone, } S=1000 \\
D=1200,2000\end{array}$ & $d=150, \mathrm{ISI}=750$ & $1-15$ & $\begin{array}{l}\text { 2000-Hz deviants: negativity } \\
\text { 150-350 msec } \\
\text { 1200-Hz deviants: positivity only }\end{array}$ \\
\hline Hirasawa et al., 2003 & $\begin{array}{l}\text { Newborn in quiet sleep, } \\
\text { active sleep, or awake }\end{array}$ & $\begin{array}{l}\text { Pure tone, } S=1000 \\
\quad D=1100\end{array}$ & $\begin{array}{l}d=100, \mathrm{ISI}=900(\text { Experiment } 1) \\
\quad \text { variable ISI }=350,900,1400 \\
\quad(\text { Experiment } 2)\end{array}$ & $0.1-40$ & $\begin{array}{l}\text { Negativity } 150-450 \text { in all groups } \\
\text { and conditions }\end{array}$ \\
\hline Leppänen et al., 2004 & $\begin{array}{l}\text { Newborns (more mature, } \\
\text { less mature according to } \\
\text { heart period and gestational } \\
\text { age) in quiet sleep }\end{array}$ & $\begin{array}{l}\text { Pure tone, } S=1000 \\
\quad D=1100\end{array}$ & $d=74, \mathrm{ISI}=351$ & $<30$ & $\begin{array}{l}\text { Negativity in less mature newborns } \\
\text { Positivity in more mature newborns }\end{array}$ \\
\hline Fellman et al., 2004 & $\begin{array}{l}\text { Newborns, 3, 6, 9, 12, and } \\
15 \text { months (preterm and } \\
\text { full term); newborns in } \\
\text { active sleep, others awake }\end{array}$ & $\begin{array}{l}\text { Harmonic tones with } \\
\text { three partials, } S=500 \\
D=750\end{array}$ & $d=100, \mathrm{ISI}=700$ & $1-15$ & $\begin{array}{l}\text { Full-term infants, negativity } 50-150 \mathrm{msec} \\
\text { in newborns and } 150-250 \text { msec at } 3 \text {, } \\
12 \text {, and } 15 \text { months; not significant } \\
\text { at } 6 \text { and } 9 \text { months' positivity } 250-350 \\
\text { in all ages } \\
\text { Preterm infants: both components found } \\
\text { to develop later than full-term infants }\end{array}$ \\
\hline
\end{tabular}


filter with a cut-off between 0.1 and $1.0 \mathrm{~Hz}$ (see Table 1), none of which will entirely filter out the slow wave if present. Even so, Weber, Hahne, Friedrich, and Friederici (2003) found that the positive slow wave was reduced and a negativity was more clearly seen when a 1.0-Hz high-pass filter was used than when a $0.3-\mathrm{Hz}$ highpass filter was used on the same data on word stress changes in 4- and 5-month-old infants, although the negativity was not significant in either case. Trainor et al. (2003) filtered more aggressively, comparing 0.1- and 3.0-Hz high-pass filter settings, and were able to observe MMN-like negativities in some 3- and 4-month-old infants with the higher filter setting in a fine temporal discrimination task. These results suggest that filtering might serve as a useful tool for dissociating the two types of change responses.

Adults do not show the slow positive response to change, and previous work in our laboratory suggests that, in a temporal gap-detection task, there is a transition from a predominance of the positive response at 2 months to a predominance of the negative response at 6 months. To investigate further the idea that the positive response is seen predominantly in younger infants and the negative response predominantly in older infants, the present study examines responses to pitch change across age.

In adults, the neural circuits involved in generating the MMN differ somewhat depending on the specific feature change to be detected. For example, different sound features (e.g., intensity, frequency, or location) elicit MMN with different amplitudes and latencies (Deouell \& Bentin, 1998), topographic maps (Paavilainen, Alho, Reinikainen, Sams, \& Näätänen, 1991), source dipole locations (Giard et al., 1995), source models in MMN, the magnetic counterpart of the MMN, (Rosburg, 2003; Levänen, Ahonen, Hari, McEvoy, \& Sams, 1996), and activation locations in event-related functional magnetic resonance imaging studies (Molholm, Martinez, Ritter, Javitt, \& Foxe, 2005). Behavioral data also indicate that auditory discrimination for different sound features matures at different ages (for a review, see Werner \& Marean, 1996). Finding that the transition from a predominantly positive to a predominantly negative response matures at different ages for different sound features would add to the evidence that there are multiple MMN mechanisms specialized for different sound features.

Conducting a detailed study of how responses to pitch change develop across age would also be useful in that, although this information is crucial for evaluating developmental theories of MMN development, it is not currently available. Most ERP studies of pitch change tested only newborns (see Table 1 ), the exceptions being Čeponiené et al. (2000; 6-month-olds), Morr et al. (2002; 2- to 47-month-olds), Kushnerenko et al. (2002; 2- to 4-day-olds, 3-, 6-, and 9-month-olds), and Fellman et al. (2004; 2- to 4-day-olds, 3-, 6-, 9-, and 12-month- olds). The Čeponiené et al. study showed that most infants exhibit MMN-like negativity at 6 months of age, but did not test younger infants. Morr et al. did test younger infants, but grouped the results from 2- to 7 -month-olds together, precluding investigation of the brain correlates paralleling behavioral improvements in pitch discrimination during this period. Kushnerenko et al. found an MMN-like negativity followed by a positivity in $75 \%$ of infants at each age between newborn and 12 months with no significant age effect. However, in this study, individual infants showing MMN at one age did not consistently show it at another age, either older or younger. In addition, examination of the waveforms illustrated in the original article shows clear changes across age, with MMN becoming more clear with increasing age, although these are not reported to be significant. These facts suggest a potential signal to noise problem, perhaps caused by the number of infants tested or the small number of epochs obtained in individual infants (not reported). The waveforms shown in Fellman et al. clearly show a prominent slow positive wave in newborns, and MMN appears to emerge at 3 months for full-term infants, but not for preterm infants corrected for gestational age.

In sum, the question as to how the mismatch response to pitch changes develops in early infancy remains largely unanswered. The present study investigated the development of positive and negative mismatch responses to pitch changes in infants between 2 and 4 months of age using natural complex tones (piano timbre). An oddball paradigm was employed in which one piano tone, $\mathrm{C}_{5}$ ( $\mathrm{fO}=523.25 \mathrm{~Hz}$ ), acted as the standard and a different piano tone, $\mathrm{F}_{5}(\mathrm{fO}=740 \mathrm{~Hz}$ ), acted as the deviant. Dense array EEG recordings were obtained, and different band-pass filters were applied to investigate the characteristics of the two types of infant mismatch responses across age. The presence of both components at certain ages in the same infants would provide strong evidence that they represent two different neural mechanisms.

\section{METHODS \\ Participants}

A total of 39 healthy, full-term infants ranging in age from 2 to 4 months with no known hearing deficits were included in the present study. Written consent was obtained from parents for their infants' participation. The final sample consisted of fourteen 4-month-olds ( 9 female), eleven 3-month-olds ( 6 female), and fourteen 2-month-olds (11 female). All infants were awake during the testing. An additional three 2-month-olds were eliminated from the final sample because they fell asleep. Furthermore, 13 infants (six 2-month-olds, three 3-month-olds, and four 4-month-olds) were excluded from the final sample because for each of these infants, 
the mean number of artifact-free deviant trials across all 124 electrodes was less than 100.

\section{Stimuli}

Monaural piano tones were synthesized with Reason 2.0 software (Propellerhead Software, Stockholm, Sweden). Standard and deviant stimuli were piano notes $\mathrm{C}_{5}$ and $\mathrm{F}_{5}$, with fundamental frequencies of 523.25 and $740 \mathrm{~Hz}$, respectively. The duration of both stimuli was $600 \mathrm{msec}$ with a 200-msec ISI. During testing, recorded stimuli were played by E-prime 1.1 software (Psychology Software Tools, Inc., Pittsburgh, PA) on a Dell OptiPlex280 computer with an Audigy 2 platinum sound card (Creative Labs, Singapore). All stimuli were presented over a speaker (WestSun Jason Sound JS1P63, Mississauga, ON, Canada) located one meter directly in front of the participant at a level of $70 \mathrm{~dB}(\mathrm{~A})$ at the location of the infant's head, over a background noise level of $29 \mathrm{~dB}(\mathrm{~A})$.

\section{Procedure}

The infant was seated on his or her parent's lap in a sound-attenuating room (Industrial Acoustics Co., Winchester, UK). A silent video (Baby Einstein) was played to keep infants happy and still. An oddball paradigm was used in which standard stimuli were presented on $80 \%$ and deviant stimuli on $20 \%$ of the trials. Stimulus order was randomized with the constraint that at least two standards occurred between successive deviants. A complete experiment consisted of 1600 trials, but testing was stopped early if infants became fussy, so the number of trials obtained in accepted subjects across all electrodes varied between 560 and 1600, with a mean of 1186 trials.

\section{Data Acquisition and Analyses}

EEG was recorded from 124 locations on the scalp by using a Geodesic Sensor Net (Electrical Geodesics, Inc., Eugene, OR). All electrode impedances were maintained below $50 \mathrm{k} \Omega$.

The electrical potential was digitized at $1000 \mathrm{~Hz}$ for the majority of participants (14 participants were digitized at $250 \mathrm{~Hz}$ ). The online recording was referenced to the vertex (electrode $\mathrm{Cz}$ in the 10/20 system) with a band-pass filter of $0.1-400 \mathrm{~Hz}$.

To investigate the ERP components within different frequency bands, three different band-pass filter settings were implemented offline: 0.5-20, 3-20, and 0.5-3 Hz. Roll-off for all filters was set to $24 \mathrm{~dB} /$ oct. The filtered continuous data were then segmented into 700-msec epochs, including a 100-msec prestimulus-onset baseline. EEG responses exceeding $\pm 120 \mu \mathrm{V}$ in any epoch were considered artifact and omitted from averaging. The remaining standard and deviant trials were averaged separately, excluding the standard trials immediately following deviant trials. Because it is only possible to obtain a small number of trials from each infant, the above rejection process was carried out for each electrode individually in order to remove the trials contaminated by artifacts (mainly due to blinks, eye or head movement) in electrodes near the noise source while preserving the trials in relatively unaffected electrodes. For each infant and for each electrode, the mean number of artifact-free deviant trials was counted; if the mean number across all 124 electrodes was less than 100 , the data from that infant were excluded from further analysis. The mean numbers of accepted deviant trials across all infants and all electrodes were as follows: 2-month-olds: $M=197, S D=25$; 3-month-olds: $M=213$, $S D=18$; 4-month-olds: $M=231, S D=22$. The averaged waveforms were then baseline corrected and referenced to an average reference. Difference waves were obtained by subtracting the standard from the deviant waveforms. Grand average difference waves were computed for each age group. Voltage maps were computed at the peak latency of the fast negative, fast positive, and slow positive waves based on the grand averaged difference waves for each age group.

For statistical analysis, 94 electrodes were selected to be divided into five groups for each hemisphere (Figure 1), and the waveforms for all electrodes in each group were averaged together to represent scalp brain responses at the frontal (20 electrodes), central (20 electrodes), parietal (20 electrodes), occipital (16 electrodes), and temporal (18 electrodes) regions. Because we were primarily interested in the development of MMN, the temporal regions were not analyzed, as they could potentially contain overlapping components such as the T complex. Thirty electrodes were excluded from the above averages due to the following considerations: 9 electrodes in the forehead near the eyes in order to further reduce the contamination of eye movement artifacts, 12 electrodes at the edge of the Geodesic net to reduce contamination of face and neck muscle movement, and 9 electrodes in the midline to enable comparison of the EEG response between hemispheres.

In the 3- to 20-Hz band-pass condition, in order to test which part of the difference wave was significantly different from zero in each age group, two-tailed $t$ tests were calculated at each time point of the difference wave across all infants in that age group. The peak latency and amplitude of the MMN-like negativity were measured in each infant at each of the eight regions defined in Figure 1. The negativity was defined as the largest negative peak between 100 and $300 \mathrm{msec}$ at frontal and central regions (and as the largest positive peak between 100 and 300 msec at parietal and occipital regions due to the polarity inversion) and the positivity following the negativity was defined as the largest positive peak between 200 and $400 \mathrm{msec}$ following the negative peak at frontal and central regions (and as the largest negativity in this window at parietal and 


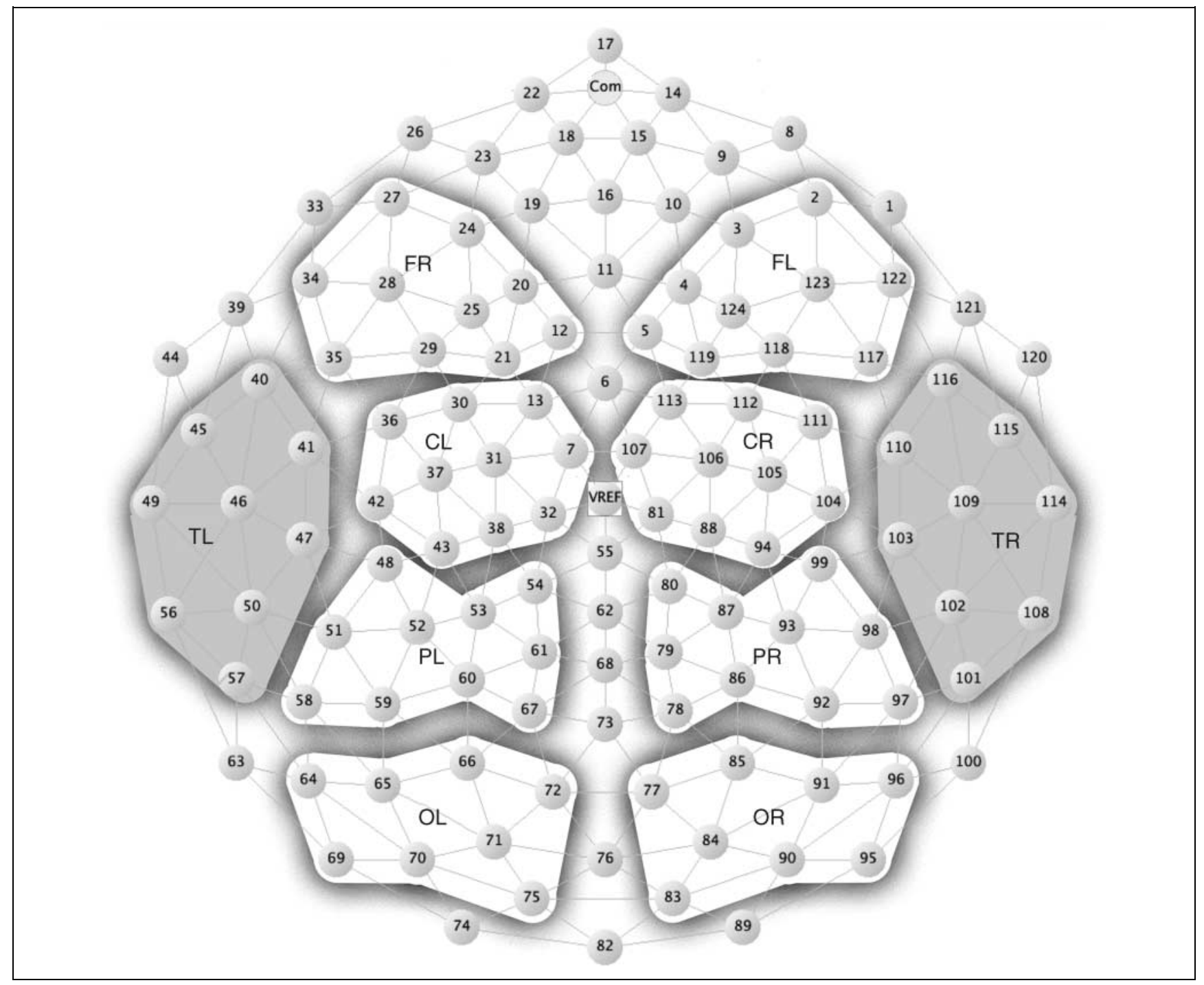

Figure 1. The grouping of electrodes in the Geodesic net (see Methods for details). Ninety-four out of 124 electrodes were selected to be divided into five groups (frontal, central, parietal, occipital, and temporal) for each hemisphere. Each region included 16 to 20 channels. The waveforms for all channels in each region were averaged together to represent EEG responses from that scalp region. The other 30 out of 124 channels were excluded from further analysis to avoid artifacts and enable comparison between hemispheres. The temporal regions were not used in the analyses.

occipital regions). Separate three-way analyses of variance (ANOVAs) were calculated for the peak latencies and absolute values of the amplitudes to test whether they varied significantly across age, hemisphere, and brain region.

For the $0.5-$ to $3-\mathrm{Hz}$ band-pass condition, the component of interest was the slow positive wave. In order to compare the standard and deviant waveforms under this filter setting, the amplitude and latency of the slow positive peak between 100 and $400 \mathrm{msec}$ in each case was identified. This time window was chosen because the slow wave peaked around $250 \mathrm{msec}$ and extended from about 100 to $400 \mathrm{msec}$. ANOVAs were used to test whether the slow positive wave differed significantly across age, hemisphere, and region.

The Greenhouse-Geisser correction was applied to all within-subjects measures with more than two levels in all of the above ANOVA tests. The Tukey HSD test was used for post hoc comparisons. The Bonferroni correction was used for within-subject comparisons.

\section{RESULTS}

\section{Description of Waveforms}

Group average ERP waveforms of the standard and deviant waves for each of the electrode groups (bandpass filter setting: $0.5-20 \mathrm{~Hz}$ ) across all 2-, 3-, and 4-month-olds are shown in Figure 2. Two-month-old deviant and standard waveforms were dominated by a broad positive slow wave between 100 and $400 \mathrm{msec}$ at frontal and central regions, which reversed polarity at the parietal, occipital, and temporal regions. The amplitude of the slow frontal positive component was larger 


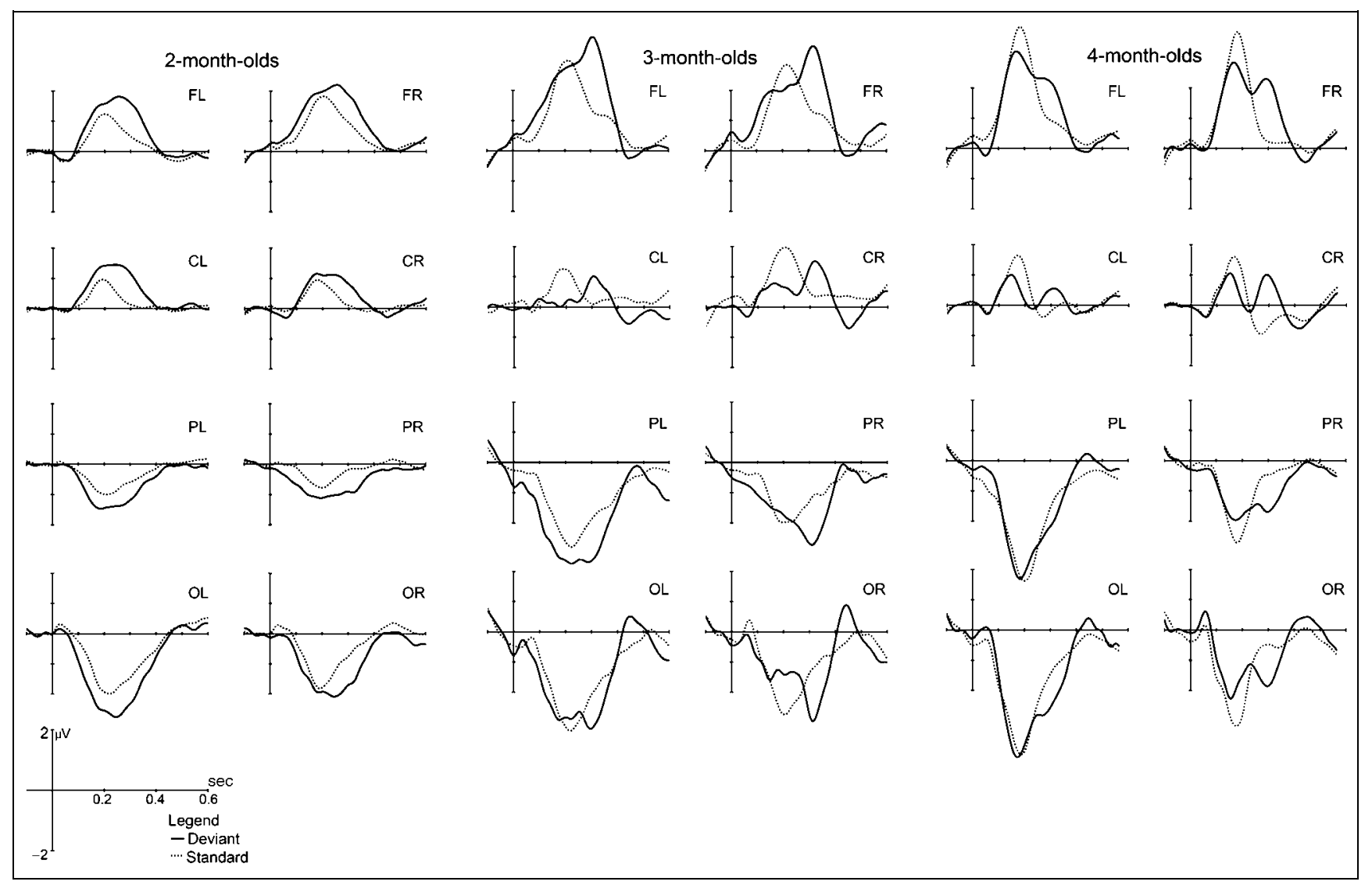

Figure 2. Grand average waveforms of the standard and deviant waves for each of the three age groups (left: 2-month-olds; middle: 3-month-olds; right: 4-month-olds) for all eight scalp regions with band-pass filtering between 0.5 and $20 \mathrm{~Hz}$.

in deviant than in standard waves during the period between about 200 to $400 \mathrm{msec}$ (see difference waves, Figure 3). Similar broad positive components were also observed in the standard and deviant waves for 3-montholds, but in this age group, the deviant waves were more negative than the standard waves between 150 to 250 msec at frontal sites and more positive between 250 and $350 \mathrm{msec}$. This gave rise to a difference wave pattern with a small MMN-like negativity around $200 \mathrm{msec}$ followed by a positivity around $300 \mathrm{msec}$. Both components reversed polarity at posterior sites (Figure 3). For 4-month-olds, the positive component was less spread out in time in the standard waves and the deviant waves showed a double peak pattern with two overlapping positive peaks. Difference waves showed the same two fast components as in the 3-month-olds (Figure 3). Figure 3 (bottom) compares the difference waves across the three age groups at electrode Fz.

This transition of the infant mismatch response from a slow positive wave to a MMN-like negativity is similar to that reported by Trainor et al. (2003) for gap discrimination, although the transition appears to occur earlier for pitch discrimination ( 2 to 4 months of age) than for gap discrimination ( 4 to 6 months of age). Additionally, the present experiment found that the adult MMN-like negativity observed in 3-and 4-month-olds and the slow positive difference wave in 2-month-olds, overlapped in latency range; thus, the slow positive wave might potentially mask the fast negativity at some ages. Because it is clear that the slow positive wave and the faster MMNlike negativity differ in frequency characteristics (see also Trainor et al., 2003; Weber et al., 2003), different band-pass filter settings were applied to isolate these two components and further study their developmental trajectories.

\section{Development of MMN-like Negativity and P3a-like Positivity: Results under 3- to 20-Hz Band-pass Filtering}

When the zero phase shift band-pass filter between 3 and $20 \mathrm{~Hz}$ was applied, the slow components were largely filtered out. In the obtained grand average difference waves (Figure 4), a negativity around $200 \mathrm{msec}$ followed by a positivity can be observed in all three age groups.

Paired $t$ tests were employed to determine the latencies at which the amplitudes of deviant and standard waves were significantly different (see bars over difference waves in Figure 4). The MMN-like negativity around 200 msec was significant only at the left frontal (FL) and right frontal (FR) regions in 2-month-olds but it achieved 


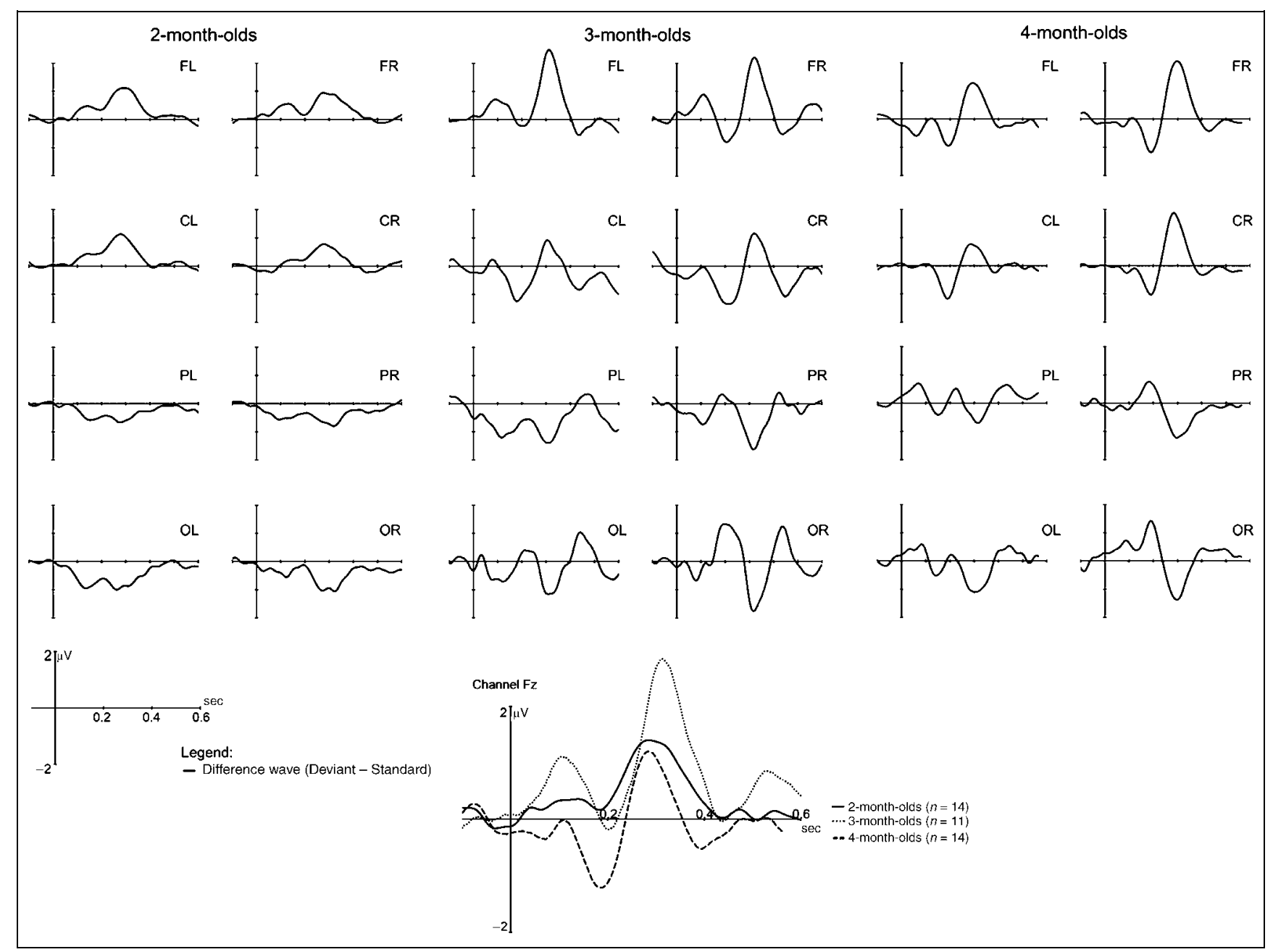

Figure 3. Grand average difference waves (deviant - standard wave) for each of the three age groups (left: 2-month-olds; middle: 3-month-olds; right: 4-month-olds) for all eight scalp regions with band-pass filtering between 0.5 and $20 \mathrm{~Hz}$. Difference waves at electrode Fz are overlaid for the three age groups (bottom).

significance at six out of eight regions in the 3-montholds and at all eight regions in the 4-month-olds. The positivity following the negativity around $300 \mathrm{msec}$ was also significant only at the FL and FR regions in 2-montholds but was significant in seven regions in 3-month-olds and in all regions in 4-month-olds.

To examine how the MMN-like negativity and the following positivity changed by age, region, and hemisphere, the peak latencies and absolute amplitudes of the MMN-like negativity (or the following positivity) in all three age groups were measured for each infant in all eight regions and subjected to three-way repeated measures ANOVAs. The dependent variable was peak latency or amplitude (separate ANOVAs for latency and amplitude). The within-subject factors were hemisphere (left, right) and brain region (frontal, central, parietal, occipital). The single between-subjects factor was age $(2,3$, and 4 months).

For the peak latency of the MMN-like component, the main effects of age, $F(2,36)=6.08, p<.005$; hemi- sphere, $F(1,36)=10.08, p<.003$; and region, $F(3,108)=$ $3.32, p=.02$, were significant. Tukey post hoc tests indicated that the peak latencies in 2-month-olds $(M=$ $214 \mathrm{msec})$ and 3-month-olds $(M=212 \mathrm{msec})$ were significantly longer (2- vs. 4-month-olds, $p=.007$; 3- vs. 4-month-olds, $p=.03)$ than in 4-month-olds $(M=$ $199 \mathrm{msec})$. For hemisphere, latencies were shorter $(p<.003)$ in the right hemisphere $(M=205 \mathrm{msec})$ than in the left hemisphere $(M=212 \mathrm{msec})$. Post hoc tests indicated significant regional differences only between the parietal $(M=214 \mathrm{msec})$ and central $(M=$ $204 \mathrm{msec}, p=.04$ ) regions.

For the absolute peak amplitude of the MMN-like component, the ANOVA showed significant main effects for age, $F(2,36)=10.85, p<.001$; hemisphere, $F(1,36)=7.38, p=.01$; and region, $F(3,108)=3.55$, $p=.02$. Post hoc tests indicated that the amplitudes of the MMN-like component in 3-month-olds $(M=$ $1.06 \mu \mathrm{V})$ and 4-month-olds $(M=1.22 \mu \mathrm{V})$ were larger (3- vs. 2-month-olds, $p=.008$; 4- vs. 2-month-olds, 


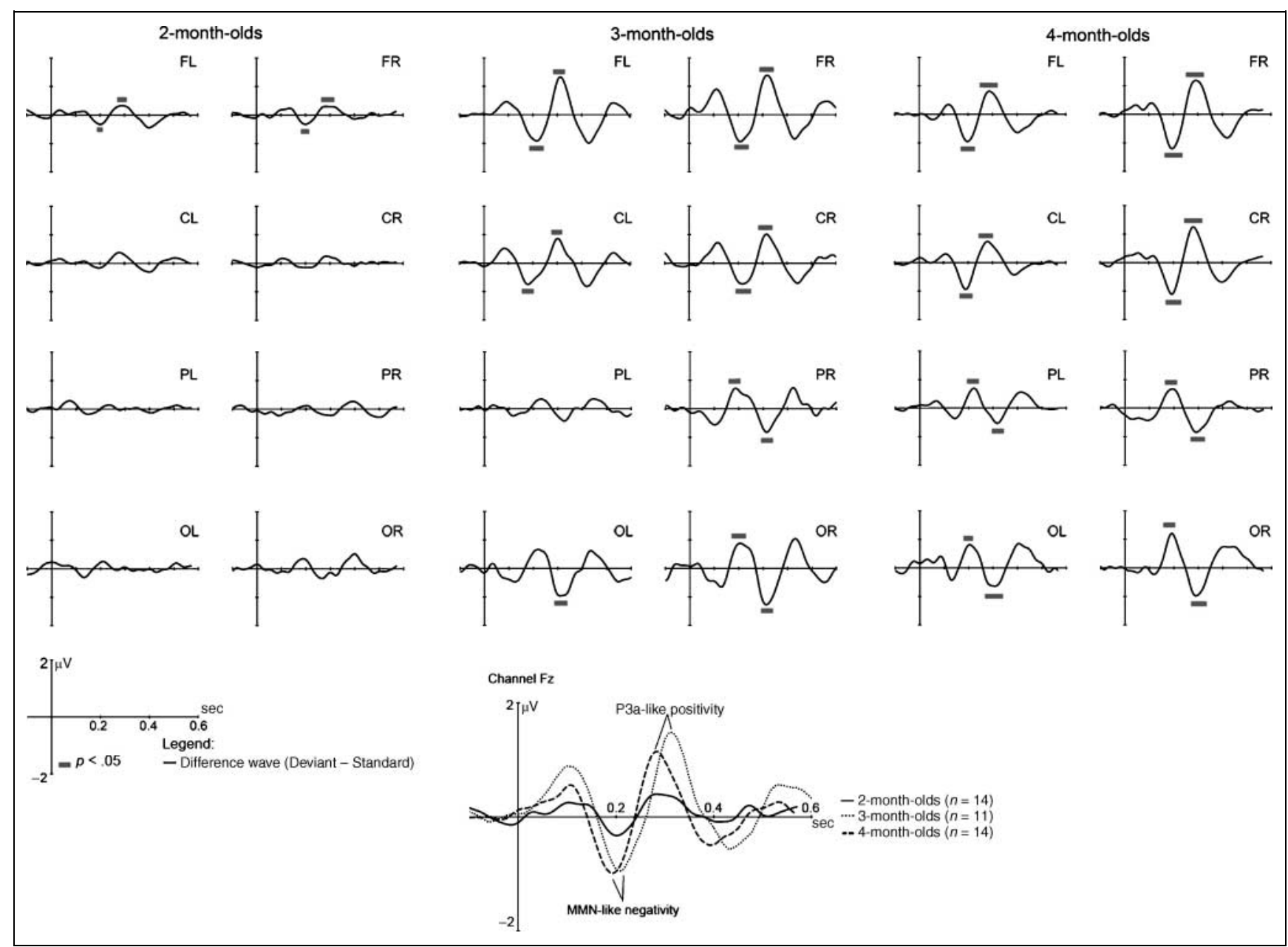

Figure 4. Grand average difference waves (deviant - standard wave) for each of the three age groups (left: 2-month-olds; middle: 3-month-olds; right: 4-month-olds) for all eight scalp regions with band-pass filtering between 3 and $20 \mathrm{~Hz}$. Bars indicate regions in which the waveforms are significantly different from zero. Difference waves at electrode Fz are overlaid for the three age groups (bottom).

$p<.001)$ than in 2-month-olds $(M=0.55 \mu \mathrm{V})$. The main effect of hemisphere reflected significantly larger $(p=$ $.01)$ amplitudes in the right $(M=1.03 \mu \mathrm{V})$ than in the left hemisphere $(M=0.86 \mu \mathrm{V})$. The main effect of region arose from the fact that the amplitude of MMN-like negativity was smaller in the parietal region $(M=.82 \mu \mathrm{V})$ than in the frontal $(M=1.02 \mu \mathrm{V}, p=.02)$ and occipital $(M=1.01 \mu \mathrm{V}, p=.01)$ regions.

The positivity following the negativity showed nearly identical effects as with the MMN-like negativity. For the peak latency of the positivity following the negativity, the main effects of age, $F(2,36)=15.62, p<.001$; hemisphere, $F(1,36)=4.87, p=.03$; and region, $F(3,108)=$ $3.47, p=.02$, were significant. Post hoc tests indicated that the peak latencies in 2-month-olds ( $M=322 \mathrm{msec})$ and 3-month-olds $(M=316 \mathrm{msec})$ were significantly earlier (2- vs. 4-month-olds, $p<.001$; 3- vs. 4-montholds, $p<.001)$ than in 4-month-olds $(M=293 \mathrm{msec})$. For the hemisphere effect, latencies were shorter $(p=$ $.03)$ in the right hemisphere $(M=308 \mathrm{msec})$ than in the left hemisphere $(M=313 \mathrm{msec})$. Post hoc pairwise comparison tests with Bonferroni correction found no significant regional differences.

For the absolute peak amplitude of the positivity following the negativity, there were significant main effects of age, $F(2,36)=13.99, p<.001$; hemisphere, $F(1,36)=8.87, p=.005$; and region, $F(3,108)=8.40$, $p<.001$. Post hoc tests indicated that the amplitudes of the positivity in 3-month-olds $(M=1.24 \mu \mathrm{V})$ and 4-month-olds $(M=1.33 \mu \mathrm{V})$ were larger (3-vs. 2-montholds, $p=.001$; 4- vs. 2 -month-olds, $p<.001)$ than in 2-month-olds $(M=.575 \mu \mathrm{V})$. The peak amplitude in the left hemisphere $(M=.96 \mu \mathrm{V})$ was smaller $(p=.03)$ than in the right hemisphere $(M=1.14 \mu \mathrm{V})$. Similar to the results for the MMN-like negative peak, the parietal region had a smaller peak amplitude $(M=.859 \mu \mathrm{V})$ than the frontal $(M=1.14 \mu \mathrm{V}, p=.004)$ and occipital $(M=1.19 \mu \mathrm{V}, p<.001)$ regions.

The topographic voltage maps at the mean peak latency of the MMN-like negative peak and at the peak of the following positivity are shown in Figure 6 for each age group (top and middle). Both the MMN-like 
negativity and the following positivity have larger amplitudes in the right than in the left hemisphere, especially for the 3- and 4-month groups. Several studies suggest that the positivity following the MMN-like negativity in infants may be related to involuntary shifts of attention (Čeponiené et al., 2002; Kushnerenko et al., 2002), and hence analogous to the $\mathrm{P} 3 \mathrm{a}$ component in adults. Although the P3a only follows the MMN in adults when attention is captured, immature inhibitory attentional mechanisms in infants may result in attentional capture being the norm, and hence P3a-like processes may typically follow the MMN in infants.

\section{Positive Slow Wave: Results under 0.5- to 3-Hz Band-pass Filtering}

The 0.5- to 3-Hz band-pass filter was employed to isolate the slow positive wave as much as possible. The peak amplitudes and latencies of the positive peak in the standard and deviant waveforms (see Figure 5) in all three age groups were measured for each infant in all eight regions and subjected to two four-way ANOVAs, one with peak amplitude and one with peak latency as the dependent variables. The between-subject factors were stimulus type (standard, deviant), region (frontal, central, parietal, occipital), and hemisphere (left, right). The single within-subjects factor was age (2, 3, and 4 months).

For amplitude, the main effects of stimulus type, $F(1,36)=18.47, p<.001$; hemisphere, $F(1,36)=5.92$, $p=.02$; and region, $F(3,108)=31.52, p<.001$, were significant, as well as interactions between stimulus type and age, $F(2,36)=7.10, p=.003$, and between region and hemisphere, $F(3,108)=7.09, p<.001$. Post hoc tests indicated that the peak amplitude of the deviants $(M=2.86 \mu \mathrm{V})$ was significantly larger $(p<.001)$ than that of the standards $(M=1.84 \mu \mathrm{V})$. As to the significant stimulus type by age interaction, post hoc tests revealed that the deviant peaks were significantly larger than standard peaks in both 2 -month-olds $\left(M_{\text {deviant }}=\right.$ $2.10 \mu \mathrm{V}, M_{\text {standard }}=1.12 \mu \mathrm{V}, p<.001$ ) and 3-month-olds $\left(M_{\text {deviant }}=2.63 \mu \mathrm{V}, M_{\text {standard }}=1.93 \mu \mathrm{V}, p=.005\right)$. However, no significant peak amplitude differences were found for 4-month-olds $\left(M_{\text {deviant }}=2.399 \mu \mathrm{V}\right.$, $\left.M_{\text {standard }}=2.480 \mu \mathrm{V}\right)$. The main effect of region arose from the fact that the peak amplitude was smaller in the central $(M=1.13 \mu \mathrm{V})$ than in the frontal $(M=2.54 \mu \mathrm{V}$, $p<.001)$, parietal $(M=2.19 \mu \mathrm{V}, p<.001)$, and occipital $(M=2.57 \mu \mathrm{V}, p<.001)$ regions. Frontal peaks were also significantly larger $(p=.029)$ than parietal peaks. For

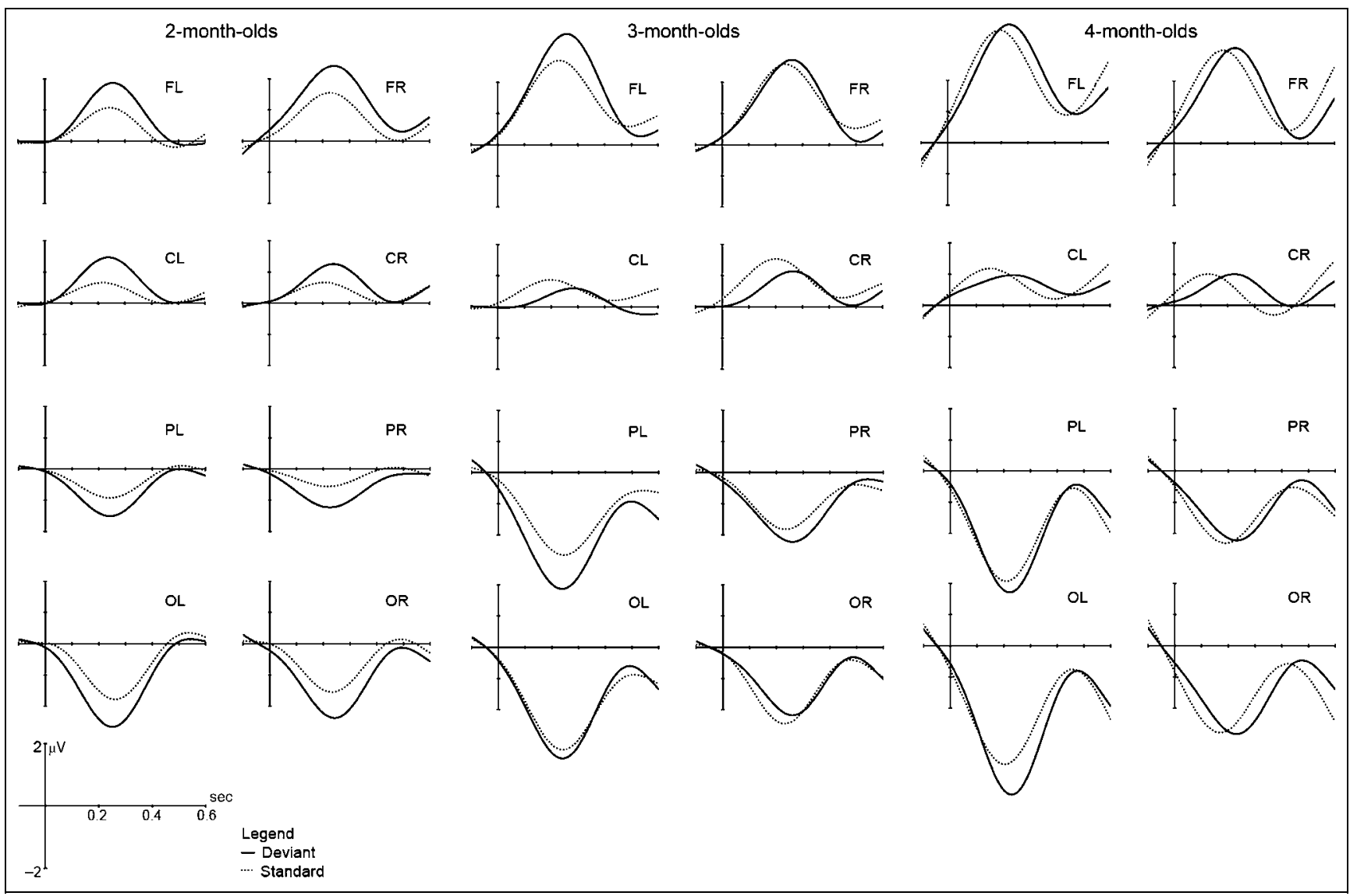

Figure 5. Grand average standard and deviant waves for each of the three age groups (left: 2-month-olds; middle: 3-month-olds; right: 4-month-olds) for all eight scalp regions with band-pass filtering between 0.5 and $3 \mathrm{~Hz}$. 
hemisphere, peak amplitudes were larger $(p=.02)$ in the left hemisphere $(M=2.28 \mu \mathrm{V})$ than in the right hemisphere $(M=1.94 \mu \mathrm{V})$. Post hoc tests revealed that the larger amplitudes in the left hemisphere were significant for parietal $(p<.001)$ and occipital $(p=$ .002) regions but not for the other two regions.

For the peak latencies, the ANOVA showed significant main effects for age, $F(1,36)=4.63, p=.016$, and stimulus type, $F(1,36)=12.95, p=.001$, and a significant interaction between age and stimulus type, $F(2,36)=9.34, p=.001$. Post hoc tests indicated that the peak latencies in 2-month-olds $(M=232 \mathrm{msec})$ and 3-month-olds ( $M=236 \mathrm{msec}$ ) were longer (2- vs. 4-month-olds, $p=.05$; 3-vs. 4-month-olds, $p=.03$ ) than in 4-month-olds $(M=207 \mathrm{msec})$. Pairwise comparisons showed that the peak latency in standard waves was significantly shorter than those of deviants in 4-montholds $\left(M_{\text {deviant }}=226 \mathrm{msec}, M_{\text {standard }}=189 \mathrm{msec}, p<.001\right)$ but there was no significant latency difference for 2 - and 3-month-olds.
The analysis outlined above indicates that the slow positive wave was significantly increased in deviants compared to standards for 2- and 3-month-olds, but not for 4-month-olds. As can be seen in the whole-head topographical voltage maps (Figure 6), the slow positive wave was larger in the left than in the right hemisphere, which is opposite to the MMN-like and P3a-like responses. It is possible that the 0.5 to $3 \mathrm{~Hz}$ filter setting did not entirely eliminate the faster MMN-like negativity and P3a-like responses. However, it is unlikely that the P3a-like response had much influence on the slow positive wave peaks. First, in 3-month-olds the 95\% confidence interval for the latency of the slow positive wave was between 220 and $252 \mathrm{msec}$, which is much earlier than the P3a-like positivity that peaked at 316 msec. Similarly, in 4-month-olds, the 95\% confidence interval for the slow positive wave was between 193 and $221 \mathrm{msec}$, which is much earlier than the P3alike positivity, which peaked at $293 \mathrm{msec}$, although the later latency of the deviant compared to standard slow
Figure 6. Whole-head topographical voltage maps for the MMN-like negativity, P3a-like positivity, and slow positive wave (not shown for 4-month-olds because the component was not significant) for each of the three age groups.

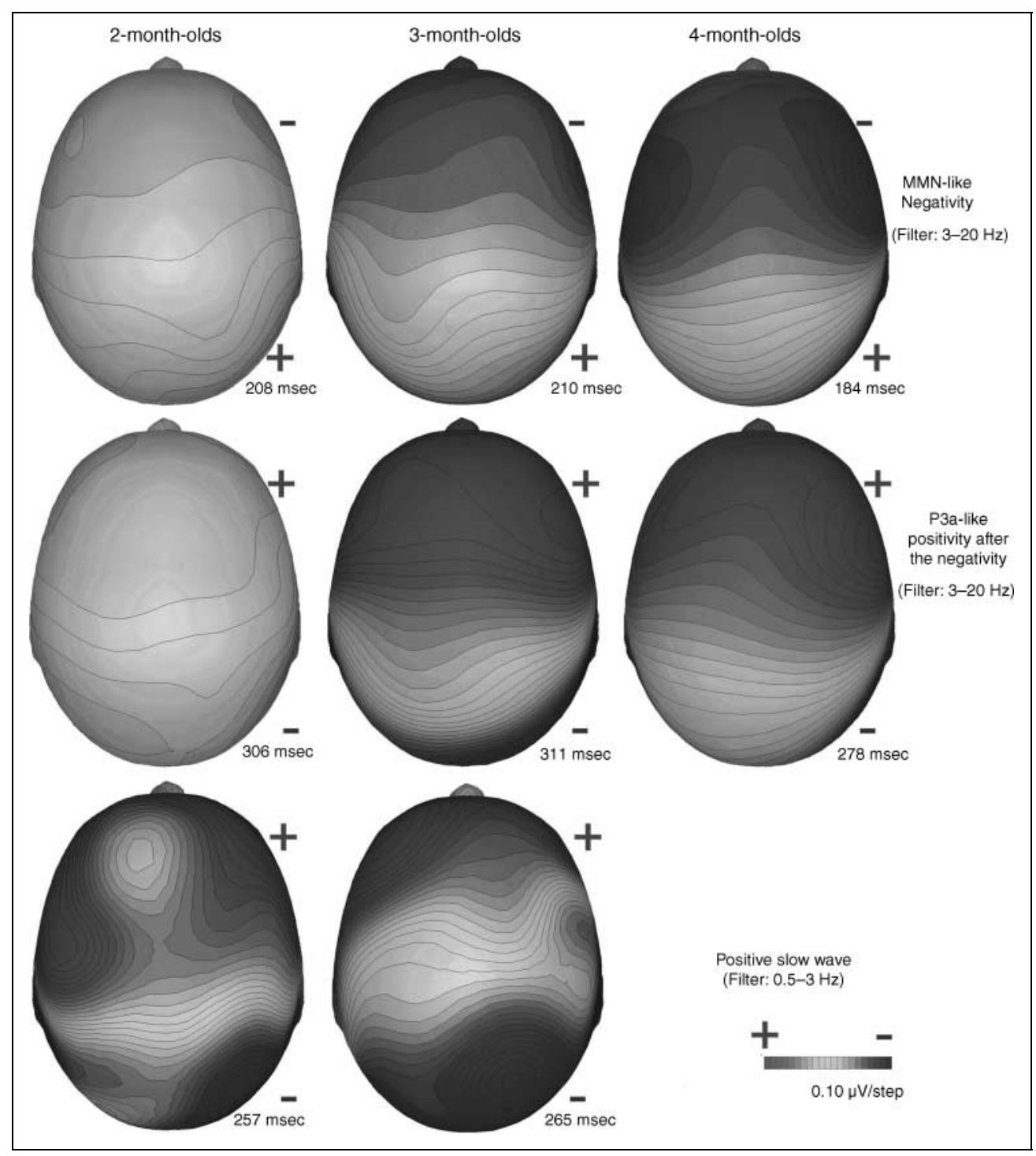


positive wave components in 4-month-olds might reflect some influence of the P3a-like component. However, if the waves under the 0.5 to $3 \mathrm{~Hz}$ filter were contaminated by the P3a-like positivity, the deviant positive peaks would be expected to be significantly larger than the standard positive peaks in the 4-montholds, who had the largest P3a-like positivity, but no differences were found in this age group.

In sum, although the MMN-like negativity increased in amplitude with age, the effect of occasional pitch changes on the amplitude of the slow positivity decreased with age, disappearing by 4 months. The fact that both the MMN-like negativity and the slow positivity were clearly present at 3 months of age further suggests that these components represent different processes in the developing brain.

\section{DISCUSSION}

In the current experiment, we recorded 2-, 3-, and 4-month-old infants' EEG responses to infrequent pitch changes in piano tones. In all three age groups, infants' responses to deviant tones were significantly different from responses to standard tones. However, the difference waves in 2-month-olds were dominated by a slow positive wave, whereas the two older groups showed a faster prominent adultlike MMN/P3a-like response pattern, although the slow positive wave also remained clear in the 3-month-old data. Two band-pass filter settings were applied to further investigate slow and fast mismatch responses. The results under the 3 to $20 \mathrm{~Hz}$ filter setting confirmed that the adultike MMN/ P3a-like responses were significant in only a few scalp regions at 2 months of age but achieved significance in most regions at 3 months of age and in all regions at 4 months of age. Both the MMN-like negativity and the following P3a-like positivity were stronger in the right than in the left hemisphere. Moreover, with increasing age, both peaks increased in amplitude and decreased in latency. On the other hand, the results under the 0.5 to $3 \mathrm{~Hz}$ filter setting indicated that the peak amplitude difference between standard and deviant slow waves was significant in 2- and 3-month-olds but not in 4-montholds. In addition, both deviant and standard slow waves were larger in the left than in the right hemisphere in 2- and 3-month-olds.

The present results demonstrate the existence of two types of infant mismatch responses. The MMN/P3a-like response pattern in older infants is similar to that reported by other studies in infants at comparable ages (e.g., Fellman et al., 2004; Kushnerenko et al., 2002; Morr et al., 2002; Trainor et al., 2001, 2003; Cheour et al., 1998; Cheour-Luhtanen et al., 1996). The slow positive wave is also similar to that reported in several studies (e.g., Sonnadara et al., 2005; Friedrich et al., 2004; Trainor et al., 2003; Friederici et al., 2002; DehaeneLambertz \& Pena, 2001; Dehaene-Lambertz, 2000;
Leppänen et al., 1999, 2004). In addition, the current study confirmed the findings of Trainor et al. (2003) and Weber et al. (2003) that different types of mismatch responses can be separated by using different band-pass filters.

As far as we are aware, the current study is among the first to report both a significant slow positive wave and a significant $\mathrm{MMN} / \mathrm{P} 3 \mathrm{a}$-like response to the same stimulus in the same infants (the 3-month-old group) analyzed in the same data set, which demonstrates that the two types of mismatch responses can indeed coexist during a certain period in early infancy. We also show that although the two responses overlap in latency, they can be separated by using different filter settings because they differ in duration. Furthermore, the MMN/ P3a-like response showed a right-hemisphere dominance, and increased in amplitude and decreased in latency with increasing age, whereas the slow positive wave was left-hemisphere dominant and decreased in amplitude with increasing age. This dissociation of the two mismatch responses in their developmental trajectories and topographical distribution patterns suggests even more strongly that they are very likely to be independent processes with independent underlying neuromechanisms.

The current results demonstrate that there is a developmental transition in infants' mismatch response from a slow positive wave to an MMN-like fast negativity in early infancy for infrequent pitch changes (Trainor et al., 2001, 2003) and is consistent with the Trainor et al. (2001, 2003) study of gap detection tasks and the study by Sonnadara et al. (2005) on sound localization tasks. However, despite the similar developmental pattern, the transition found here for pitch takes place between 2 and 4 months of age, which is earlier than that found for gap detection (4 to 6 months of age) and localization tasks (after 8 months of age). These different maturational timetables confirm our hypothesis of feature-specific MMN development. Furthermore, earlier MMN maturation for pitch discrimination than for gap detection mirrors the earlier behavioral maturation of pitch discrimination (for a review, see Werner \& Marean, 1996) in comparison to gap detection (Irwin, Ball, Kay, Stillman, \& Rosser, 1985).

A question that remains largely unanswered is the nature of the two types of mismatch responses in early infancy. In general, the characteristic slow wave component seen in early infancy is thought to result from the poorly myelinated connections between neurons in the immature brain (Paus et al., 2001; Vaughan \& Kurtzberg, 1992). The slow wave may thus disappear as the process of myelination takes place. However, this does not indicate what the increased amplitude of the slow wave in response to occasional change actually represents. It has been hypothesized that the positive slow wave may reflect a release from a refractory state (Čeponiené et al., 2002) or an automatic categorization of stimuli 
(Friedrich et al., 2004) or an immature type of $\mathrm{P} 3 \mathrm{a}$ response representing an involuntary attention shift (Kushnerenko et al., 2002). However, to date, we do not have a definitive answer to this question.

Nor are the neural generators of the slow wave clear. Trainor et al. (2003) discuss several possibilities. Because anatomical data from human autopsies indicate that the neurofilaments necessary for fast, effective synaptic communication are only present in layer I of the auditory cortex during the first months after birth (Moore \& Guan, 2001), and layer I is not involved in discriminative processes in adults, one possibility is that the slow waves involve a subcortical sink (depolarization) with a passive circuit-completing source in layer 1 . However, this seems unlikely because thalamic field potentials are not visible at the scalp in adults, and the input to layer I is nonspecific in adults. A second possibility proposed by Trainor et al. is that neurons in layer IV are depolarizing even though they do not have functional synapses (Huttenlocher \& Dabholkar, 1997), and these depolarizations are accompanied by passive returns located in layer I. The scalp potentials appear as slow waves because highly synchronized depolarization is not possible in layer IV because of the immaturity of their synaptic function.

Similarly, although several studies (e.g., Friedrich et al., 2004; Morr et al., 2002; Čeponiené et al., 2000, 2002; Cheour et al., 1998; Cheour-Luhtanen et al., 1996) suggest that the MMN-like response to change seen in infancy could represent discrimination processes in auditory cortex similar to those underlying the MMN response in adults, this interpretation also needs validation. The source of MMN is thought to be in the supragranular layers of A2, including layers II and upper III (Javitt, Steinschneider, Schroeder, Vaughan, \& Arezzo, 1994). However, according to Moore (2002) and Moore and Guan (2001), only layer I is fully functional before 4 months of age, with mature synapses beginning to develop in deeper layers (IV, V, VI) around 4 months of age, but not in layers II and upper III until after 5 years of age. Thus, the generators and underlying mechanisms of the MMN-like negativity seen in infants may in fact be quite different from that seen in adults in terms of neural mechanisms and function. More research is needed in order to investigate the nature of the mismatch response in infants and its underlying neural generators.

Overall, the current study demonstrated that there are two types of mismatch responses to infrequent pitch changes coexisting during a certain period in early infancy. The adultlike MMN/P3a-like response pattern becomes more prominent, whereas the slow positive difference wave diminishes as age increases. Furthermore, the maturational timetables according to which these mismatch responses develop are different for different stimulus features, with early emergence of the MMN-like negativity for pitch discrimination compared to gap discrimination or sound localization. The coexistence of two types of responses and the dissoci- ation of their developmental trajectories also suggests that they have separate underlying neuromechanisms.

\section{Acknowledgments}

This research was funded by a grant from the Canadian Institutes for Health Research (to L. J. T.). We thank Dorcas Yung for help in testing the infants and Jingjiang Lei for technical support.

Reprint requests should be sent to Laurel Trainor, Department of Psychology, McMaster University, Hamilton, Ontario, Canada L8S 4K1, or via e-mail: ljt@mcmaster.ca.

\section{REFERENCES}

Alho, K., Sainio, K., Sajaniemi, N., Reinikainen, K., \& Näätänen, R. (1990). Event-related brain potentials of human newborns to pitch change of an acoustic stimulus. Electroencephalography and Clinical Neurophysiology, 77, 151-155.

Čeponiené, R., Hukki, J., Cheour, M., Haapanen., M. L., Koskinen, M., Alho., K., et al. (2000). Dysfunction of the auditory cortex persists in infants with certain cleft types. Developmental Medicine \& Child Neurology, 42, 258-265.

Čeponiené, R., Kushnerenko, E., Fellman, V., Renlund, M., Suominen, K., \& Näätänen, R. (2002). Event-related potential features indexing central auditory discrimination by newborns. Brain Research, Cognitive Brain Research, 13, 101-113.

Cheour-Luhtanen, M., Alho, K., \& Sainio, K. (1996). The ontogenetically earliest discriminative response of the human brain. Psychophysiology, 33, 478-481.

Cheour, M., Alho, K., Čeponiené, R., Reinikainen, K., Sainio, K., Pohjavuori, M., et al. (1998). Maturation of mismatch negativity in infants. International Journal of Psychophysiology, 29, 217-226.

Cheour, M., Čeponiené, R., Hukki, J., Haapanen, M. L., Näätänen, R., \& Alho, K. (1999). Dysfunction in neonates with cleft palate revealed by the mismatch negativity. Electroencephalography and Clinical Neurophysiology, 110, 324-328.

Dehaene-Lambertz, G. (2000). Cerebral specialization for speech and nonspeech influences newborns' perception of speech sounds. Journal of Cognitive Neuroscience, 12, 449-460.

Dehaene-Lambertz, G., \& Dehaene, S. (1994). Speed and cerebral correlates of syllable discrimination in infants. Nature, 370, 292-295.

Dehaene-Lambertz, G., \& Pena, M. (2001). Electrophysiological evidence for automatic phonetic processing in neonates. NeuroReport, 12, 3155-3158.

Deouell, L. Y., \& Bentin, S. (1998). Variable cerebral responses to equally distinct deviance in four auditory dimensions: A mismatch negativity study. Psychophysiology, 35, 745-754.

Fellman, V., Kushnerenko, E., Mikkola, K., Čeponiené, R., Leipala, J., \& Näätänen, R. (2004). Atypical auditory event-related potentials in preterm infants during the first year of life: A possible sign of cognitive dysfunction? Pediatric Research, 56, 291-297.

Fernald, A., \& Kuhl, P. (1987). Acoustic determinants of infant preference for motherese speech. Infant Behavior and Development, 10, 279-293.

Fernald, A., \& Mazzi, C. (1991). Prosody and focus in speech to infants and adults. Developmental Psychology, 27, 209-221. 
Friederici, A. D., Friedrich, M., \& Weber, C. (2002). Neural manifestation of cognitive and precognitive mismatch detection in early infancy. NeuroReport, 13, 1251-1254.

Friedrich, M., Weber, C., \& Friederici, A. D. (2004). Electrophysiological evidence for delayed mismatch response in infants at-risk for specific language impairment. Psychophysiology, 41, 772-782.

Giard, M. H., Lavaikainen, J., Reinikainen, K., Perrin, F., Bertrand, O., Pernier, J., et al. (1995). Separate representation of stimulus frequency, intensity, and duration, in auditory sensory memory: An event-related potential and dipole-model analysis. Journal of Cognitive Neuroscience, 7, 133-143.

Hirasawa, K., Kurihara, M., \& Konishi, Y. (2003). The relationship between mismatch negativity and arousal level. Can mismatch negativity be an index for evaluating the arousal level in infants? Sleep Medicine, 3, 45-48.

Huttenlocher, P. R., \& Dabholkar, A. S. (1997). Regional differences in synaptagenesis in human cerebral cortex. Journal of Comparative Neurology, 387, 167-178.

Irwin, R. J., Ball, A. K. R., Kay, N., Stillman, J. A., \& Rosser, J. (1985). The development of temporal acuity in children. Child Development, 56, 614-620.

Jacobsen, T., \& Schröger, E. (2001). Is there pre-attentive memory-based comparison of pitch? Psychophysiology, 38, 723-727.

Javitt, D. C., Steinschneider, M., Schroeder, C. E., Vaughan, H. G., Jr., \& Arezzo, J. C. (1994). Intracortical mechanisms of mismatch negativity (MMN) generation. Brain Research, 667, 192-200.

Jusczyk, P. W., \& Derrah, C. (1987). Representation of speech sounds by young infants. Developmental Psychology, 23, 648-654.

Kessen, W., Levine, J., \& Wendrich, K. A. (1979). The imitation of pitch in infants. Infant Behavior and Development, 2, 93-99.

Kushnerenko, E., Čeponiené, R., Balan, P., Fellman, V., Huotilainen, M., \& Näätänen, R. (2002). Maturation of the auditory change detection response in infants: A longitudinal ERP study. NeuroReport, 13, 1843-1848.

Leppänen, P. H., Eklund, K. M., \& Lyytinen, H. (1997). Event-related brain potentials to change in rapidly presented acoustic stimuli in newborns. Developmental Neuropsychology, 13, 175-204.

Leppänen, P. H., Guttorm, T. K., Pihko, E., Takkinen, S., \& Lyytinen, H. (2004). Maturational effects on newborn ERPs measured in the mismatch negativity paradigm. Experimental Neurology, 190, 91-101.

Leppänen, P. H. T., Pihko, E., Eklund, K. M., \& Lyytinen, H. (1999). Cortical responses of infants with and without a genetic risk for dyslexia: II. Group effects. NeuroReport, 10, 969-973.

Levänen, S., Ahonen, A., Hari, R., McEvoy, L., \& Sams, M. (1996). Deviant auditory stimuli activate human left and right auditory cortex differently. Cerebral Cortex, 6 , 288-296.

Maxon, A. B., \& Hochberg, I. (1982). Development of psychoacoustic behavior: Sensitivity and discrimination. Ear and Hearing, 3, 301-308.

Molholm, S., Martinez, A., Ritter, W., Javitt, D. C., \& Foxe, J. (2005). The neural circuitry of pre-attentive auditory change-detection: An fMRI study of pitch and duration mismatch negativity generators. Cerebral Cortex, 15, 545-551.

Moore, J. K. (2002). Maturation of human auditory cortex: Implications for speech perception. The Annals of Otology, Rbinology, and Laryngology, 111, 7-10.
Moore, J. K., \& Guan, Y. L. (2001). Cytoarchitectural and axonal maturation in human auditory cortex. The Journal of the Association for Research in Otolaryngology, 2, 297-311.

Morr, M. L., Shafer, V. L., Kreuzer, J. A., \& Kurtzberg, D. (2002). Maturation of mismatch negativity in typically developing infants and preschool children. Ear and Hearing, 23, 118-136.

Näätänen, R., \& Alho, K. (1995). Mismatch negativity-A unique measure of sensory processing in audition. International Journal of Neuroscience, 80, 317-337.

Näätänen, R., \& Alho, K. (1997). Higher-order processes in auditory-change detection. Trends in Cognitive Sciences, 1, 44-45.

Näätänen, R., Jacobsen, T., \& Winkler, I. (2005). Memory-based or afferent processes in mismatch negativity (MMN): A review of the evidence. Psychophysiology, 42, 25-32.

Näätänen, R., Paavilainen, P., Tiitinen, H., Jiang, D., \& Alho, K. (1993). Attention and mismatch negativity. Psychophysiology, 30, 436-450.

Oades, R. D., \& Dittmann-Balcar, A. (1995). Mismatch negativity (MMN) is altered by directing attention. NeuroReport, 6, 1187-1190.

Olsho, L. W., Koch, E. G., Halpin, C. F., \& Carter, E. A. (1987). An observer-based psychoacoustic procedure for use with young infants. Developmental Psychology, 23, 627-640.

Olsho, L. W., Schoon, C., Sakai, R., Turpin, R., \& Sperduto, V. (1982). Auditory frequency discrimination in infancy. Developmental Psychology, 18, 721-726.

Paavilainen, P., Alho, K., Reinikainen, K., Sams, M., \& Näätänen, R. (1991). Right hemisphere dominance of different mismatch negativities. Electroencephalography and Clinical Neurophysiology, 78, 466-479.

Paus, T., Collins, D. L., Evans, A. C., Leonard, G., Pike, B., \& Zijdenbos, A. (2001). Maturation of white matter in the human brain: A review of magnetic resonance studies. Brain Research Bulletin, 54, 255-266.

Picton, T. W., Alain, C., Otten, L., Ritter, W., \& Achim, A. (2000). Mismatch negativity: Different water in the same river. Audiology \& Neuro-Otology, 5, 111-139.

Pihko, E., Leppänen, P. H. T., Eklund, K. M., Cheour, M., Guttorm, T. K., \& Lyytinen, H. (1999). Cortical responses of infants with and without a genetic risk for dyslexia: I. Age effects. NeuroReport, 10, 901-905.

Plantinga, J., \& Trainor, L. J. (2005). Memory for melody: Infants use a relative pitch code. Cognition, 98, 1-11.

Rosburg, T. (2003). Left hemispheric dipole locations of the neuromagnetic mismatch negativity to frequency, intensity and duration deviants. Brain Research, Cognitive Brain Research, 16, 83-90.

Schröger, E. (1998). Measurement and interpretation of the mismatch negativity. Behavior Research Methods, Instruments, \& Computers, 30, 131-145.

Sinnott, J. M., \& Aslin, R. N. (1985). Frequency and intensity discrimination in human infants and adults. Journal of the Acoustical Society of America, 78, 1986-1992.

Sonnadara, R. R., Hotson, L., \& Trainor, L. J. (2005). Event-related potentials elicited by occasional changes in sound location across the first 8 months of life. Presented at the Society for Psychophysiological Research 44th Annual Meeting, Lisbon.

Sussman, E., Ritter, W., \& Vaughan, H. G., Jr. (1998). Attention affects the organization of auditory input associated with the mismatch negativity system. Brain Research, 789, 130-138.

Trainor, L. J., \& Desjardins, R. N. (2002). Pitch characteristics of infant-directed speech affect infants' ability to 
discriminate vowels. Psychonomic Bulletin \& Review 9, 335-340.

Trainor, L. J., McFadden, M., Hodgson, L., Darragh, L., Barlow, J., Matsos, L., et al. (2003). Changes in auditory cortex and the development of mismatch negativity between 2 and 6 months of age. International Journal of Psychophysiology, 51, 5-15.

Trainor, L. J., Samuel, S. S., Desjardins, R. N., \& Sonnadara, R. R. (2001). Measuring temporal resolution in infants using mismatch negativity. NeuroReport, 12, 2443-2448.

Trainor, L. J., \& Trehub, S. E. (1992). The development of referential meaning in music. Music Perception, 9 , 455-470.

Trehub, S. E. (2001). Musical predispositions in infancy. Annals of the New York Academy of Sciences, 930, 1-16.
Vaughan, H. G., Jr., \& Kurtzberg, D. (1992). Electrophysiologic indices of human brain maturation and cognitive development. In M. R. Gunnar \& C. A. Nelson (Eds.), Minnesota symposia on child psychology (pp. 1-36). Hillsdale, NJ: Erlbaum.

Weber, C., Hahne, A., Friedrich, M., \& Friederici, A. D. (2003). Discrimination of word stress in early infant perception: Electrophysiological evidence. Cognitive Brain Research, 18, 149-161.

Werker, J. F., \& McLeod, P. J. (1989). Infant preference for both male and female infant-directed talk: A developmental study of attentional and affective responsiveness.

Canadian Journal of Psychology, 43, 230-246.

Werner, L. A., \& Marean, G. C. (1996). Human auditory development. Boulder, CO: Westview Press. 